\title{
E-LEARNING AND AMRES IN TEACHING ARCHITECTURE
}

\author{
A. Djukic; N. (1) T.Mrdjenovic (2); J. Jokovic (3) \\ Department for Urbanism $(1,2)$ \\ University of Belgrade $(1,2)$ \\ Department for Telecommunications (3) \\ University of Nis (3) \\ adjukic@afrodita.rcub.bg.ac.rs (1)
}

\begin{abstract}
ICT is not only the additional instrument of the Information Society, but also an important catalyst and tool for inducing educational reforms that change our students into productive knowledge workers. There are notions that students should be trained to learn more autonomously and to get access to and digest information more independently which could provide a good basis for life long learning. The research will discuss pros and cons of using AMRES as an e-learning academic platform in academic education in theoretical and practical courses at engineering and architectural studies. The hypothesis is that e-learning concept provides attitude change among students in knowledge development regarding the course subject. The hypothesis will be tested inside main approaches and attitudes of using ICT in knowledge development, using case study using AMRES at the courses Design of Open Public Spaces and Studio Project 3, both at Bachelor studies at the Faculty of Architecture, University of Belgrade.
\end{abstract}

Key words: e-learning, Amres, ICT, architecture 


\section{INTRODUCTION}

E-society frames different areas of our everyday life that creates various networks in communication. It influences different ways of acquiring and developing academic knowledge using the concept of e-learning. ICT is not only the additional instrument of the Information Society, but also an important catalyst and tool for inducing educational reforms that change our students into productive knowledge workers. Across the past twenty five years the use of ICT has changed approach of learning in the higher education. The new way of learning requires effective integration of technologies into existing context of teaching in order to provide learners with knowledge of specific subject areas, to promote meaningful learning and to enhance professional productivity [1]. On the other hand, education is highly socially oriented and personal contacts and feed backs are necessary for both sides - teachers and students. Especially in education of engineers.

However, education used to be a matter of uni-directional transfer of information: from the teacher to the student, while ex-cathedra method was the most common one. There are notions that students should be trained to learn more autonomously and to get access to and digest information more independently which could provide a good basis for life long learning. The new pedagogical models which include ICT should provide: weaker students with additional instruction; reduces differences in entrance level between students; teach students to search for information, process data, and present information; exchanging information and knowledge between students in the same or from similar fields as well as to teach students how to control their own learning progress and to improve their knowledge throughout their professional career. On the other hand, the main role of teachers/professors will be to act as experts and leaders to motivate learning.

Four different rationales that drive policies related to the integration of ICT in education are recognized by Hawkridge:

- an economic rationale: the development of ICT skills related to future jobs and careers;

- a social rationale: the students should use computers in order to become responsible and well-informed citizens;

- an educational rationale: ICT is supportive tool for improving teaching and learning process;

- a catalytic rationale: ICT is expected to accelerate educational innovations. [2]. ICT can provide strong support for new requirements of curricula, such as: access to a variety of information sources; access to a variety of information forms and types; student-centered learning; settings based on information access and inquiry; learning environments centered on problem; and teachers as coaches and mentors rather than content experts [2;3;4].

\section{APPROACHES TO E-LEARNING}

According to Avriam and Tami ICT can be considered in three paradigms of using ICT in developing academic knowledge: (1) The Technocrat paradigm, (2) The Reformist Paradigm; (3) The Holistic Paradigm [1]. The paradigms emerged 
from different approaches and attitudes in using ICT within curricula. These approaches and attitudes are starting point in defining criteria for measuring elearning types and attitude change, where approaches stands for aims and nature of introducing and implementing ICT in education, and attitudes nature and extend towards change in education using ICT.

The different approaches: Administrative, Curricular, Didactic, Organizational, Systematic, Cultural and Ideological will be presented, linked with attitudes: Agnostic, Conservative, Moderate, and Radical Extreme Radical and interconnected with three paradigms mentioned above.

According the administrative approach ICT per se is enough for making change in any kind of working process including knowledge development. It is assumed that number and quality of equipment (computers, software, network, databases, web platforms, etc.) will contribute to the behavioral change without any other measure or linkage. [1].

On thee other hand, the curricular approach promotes integration between ICT and curricula at some stage of realization. Actually, ICT is seen as a servant to specific goal within the teaching curricula. Under this position authors differ two types: (a) the disciplinary form where ICT is learned and practiced as separate discipline without linkages to other subjects or disciplines; (b) the integrative form where ICT is an integral part of prevailing curriculum usually in the context of natural sciences. [1].

The didactic approach alike curricular one goes one step beyond, seeing ICT as a neutral tool that serves different curricula programs, therefore represents a higher level of inter disciplinarity. Therefore, the model of ICT that supports curricula is neutral, following general aims of developing knowledge. [1].

Furthermore, the organizational approach lean on previous one, hence involves the thought that introduction of ICT in learning means necessity to do organizational changes within educational system as well as interpretation and acquiring knowledge. [1].

The systematic approach stands for integration of organizational changes and ICT, on the level of structural reforms within academic system in the direction that this kind of new system allow more distance-learning or even virtual schooling, changing the attitude towards time, place, curriculum and other connected attributes of the academic-educational system. [1].

Antlike previously described cultural approach recognizes that ICT involves cultural changing mode, meaning ICT revolution is a way of cultural revolution in all patterns of everyday life including education and learning process. [1]. It is somehow linked to the Castells network society as a superstructure of information society and revolution [5]. What is important here is that information society, ICT revolution, establish, and develop new kind of social networks that never existed before. Therefore, network society needs new kind of educational system, patterns, methods and tools.

Furthermore, Pelgrum makes differences between role and ways of education in Industrial and Information society. According to him in Information society any type of school should be integral part of it with information openly available, 
unlike in Industrial society where school is isolated and most of information on school functioning is confidential [6].

In line with this, ideological approach stands for critical thinking, evaluating, considering values in introducing and using ICT in education. Therefore, this approach question why, how and when ICT should be used in academic education.

Regarding attitudes, first one agnostic do not think that ICT can bring qualitative changes in education, as according to them it is just another tool. This attitude is complementary only to the administrative and curricular approach as does not consider ICT in a form of network society. The second one, conservative, stands for minimal changes in educational system regarding ICT and is not compatible with administrative approach. Moderate attitude is for those who are for greater integration of ICT, however still leaning on predominant educational system. Unlike previous, radical and extreme radical approaches sees ICT as strong force for educational change towards network society [1].

The approaches with attitudes frame three paradigms: The Technocratic, The Reformist and The Holistic one. Technocratic paradigm combines agnostic or conservative attitude with administrative or curricular approach. The Reformist one promote inter disciplinarity, collaborationisms with moderate attitudes. The Holistic paradigm stands for cultural and ideological approaches with conservative, radical or extreme radical attitudes [1].

\section{CONSIDERING AMRES WITHIN THE PARADIGMS}

This chapter will position AMRES regarding defined approaches and attitudes giving general overview on its structure, nature and aims. Before starting presenting AMRES it is necessary to establish criteria for categorize types of approaches in using ICT in education and research. Criteria will be connected to the approaches (as attitudes are linked towards approaches) (Table 1.).

CRITERIA FOR MEASURING E-LEARNING APPROACHES:

1. number and quality of ICT equipment, network, security;

2. integration of usage ICT in overall curricula;

3. integration of usage ICT in specific curricula, tailor made ICT system;

4. moderate or high level of acceptance among users;

5. number and types of procedures, protocols, tools for using ICT in education;

6. integration of ICT in all organizational units in educational process;

7. types and number of discussion groups in regards to ways of introducing ICT in specific curricula and overall educational process. 
Table 1. Predominant approach according to criteria

\begin{tabular}{|c|c|c|c|c|c|c|c|}
\hline $\begin{array}{c}\text { App/C } \\
\text { riteria }\end{array}$ & $\begin{array}{c}\text { Adm } \\
\text { in. }\end{array}$ & curr. & did & oper. & syst & cult & ideo. \\
\hline 1. & $\mathrm{X}$ & $\mathrm{X}$ & $\mathrm{X}$ & $\mathrm{X}$ & $\mathrm{X}$ & $\mathrm{X}$ & $\mathrm{X}$ \\
\hline 2. & & $\mathrm{X}$ & $\mathrm{X}$ & $\mathrm{X}$ & $\mathrm{X}$ & $\mathrm{X}$ & $\mathrm{X}$ \\
\hline 3. & & & $\mathrm{X}$ & $\mathrm{X}$ & $\mathrm{X}$ & $\mathrm{X}$ & $\mathrm{X}$ \\
\hline 4. & & & & $\mathrm{X}$ & $\mathrm{X}$ & $\mathrm{X}$ & $\mathrm{X}$ \\
\hline 5. & & & & & & $\mathrm{X}$ & $\mathrm{X}$ \\
\hline 6. & & & & & & $\mathrm{X}$ & $\mathrm{X}$ \\
\hline 7. & & & & & & & $\mathrm{X}$ \\
\hline
\end{tabular}

"AMRES" was established in order to build, develop and manage the education and research computer network of the Republic of Serbia, as well as to actualize the rights of pupils and students to education and information. Using the informatics and Internet infrastructure, and computes network, AMRES provides the education and research organizations and other members with access and use of the Internet and information services in the country, as well as the connection with national and international networks of such type.

In particular, AMRES has the following responsibilities:

- managing the education and research computer network of the Republic of Serbia;

- designing, developing, building, maintaining and improving the computer and communication infrastructure and services which are connecting the education and research institutions in a single computer network;

- connecting and cooperating with national and international education and research computer networks;

- coordinating the works of network hubs and computer centers withing universities and other organizational units on faculties and institutes;

- expertise help and education of users of the education and research computer network services'

- adult education.

In performing its work, AMRES provides the education organizations and organizations which perform a scientific-research work with services of using the education and research computer network of the Republic of Serbia.

In accordance with current AMRES act, AMRES users are:

- Universities and Faculties;

- high education systems;

- primary and secondary schools;

- accredited scientific-research organizations;

- researchers and students of doctor studies, and scholars

- Serbian Academy of Sciences and Art;

- Matica srpska;

- other organizations in accordance to the law that regulates the scientificresearch work;

- institutions which promote the achievements in science and education;

- scientific-development units within companies. 
Other legal entities" [7].

E-learning service aims to modernize educational process at faculties using different ICT instruments and tools. It main characteristics is general modeling for overall curricula which is dedicated for teachers and students at all faculties and institutions mentioned above, and who do not still have capacities for autonomous conception and full implementation of ICT. [7]

Main characteristic of AMRES regarding the criteria are shown in Table 2.

Table 2. Positioning AMRES within different ICT approaches

\begin{tabular}{|l|l|l|l|l|l|l|l|}
\hline $\begin{array}{l}\text { Crite } \\
\text { ria/A } \\
\text { pp }\end{array}$ & $\begin{array}{l}\text { Ad } \\
\text { min. }\end{array}$ & curr. & did. & oper. & syst. & cult. & ideo. \\
\hline 1. & & & $\mathrm{x}$ & $\mathrm{x}$ & & & \\
\hline 2. & & & $\mathrm{x}$ & $\mathrm{x}$ & & & \\
\hline 3. & & & $\mathrm{x}$ & $\mathrm{x}$ & & & \\
\hline 4. & & & $?$ & $?$ & & & \\
\hline 5. & & & & & & & \\
\hline 6. & & & & & & & \\
\hline 7. & & & & & & & \\
\hline
\end{tabular}

Table 3. shows that AMRES with its e-learning service promotes didactic towards operational approach in level of integration ICT in everyday learning activities. The level of acceptance among all users should position it stronger within the approaches, however the questionnaire is needed to be done at all levels. Therefore, the case study and questionnaire that will be presented in the next chapter can only say more about attitudes among one groups of students at Faculty of Architecture in Belgrade.

\section{CASE STUDY: USING AMRES IN THE COURSE REDESIGN OF OPEN PUBLIC SPACE AND STUDIO PROJECT 3}

This chapter will give an insight regarding attitudes among students in using elearning AMRES service at he course Urban design of open public space. The chapter will further map AMRES in regards to the specific subject.

The one semester theoretical compulsory course Urban design of open public spaces for students of Architecture at the Faculty of Architecture, University of Belgrade is taught in the second semester of Bachelor studies. Besides the theoretical course, there are a short exercises after the lectures when students draw cognitive maps according their impressions from the lecture and related to the concrete area in Belgrade. The objective of the course is to introduce students to the fundamentals of urban design and familiarize them with the basic elements of designing open urban spaces. The Urban Design of open public 
spaces starts from the premise that the architecture students shall first become acquainted with the contemporary approach to urban development.

The teaching process of the course is based on actual theoretical consideration in Urban Design and it integrates physical and human dimensions of urban space [8]. New models, methods and techniques, adapted for the students at second semester are presented to them. The process of learning is "step-by-step" and the steps are cyclic connected. Two major groups of activities that simulate urban qualities are recognized: professional acting in designing and planning and cognition function of urban space [8]. Ex-cathedra lectures are interactive, multimedial and provoke discussion between professor and students. On the other hand, another way of communication is offered through AMRES or od Faculty server. All lectures are posted on AMRES, students can get additional literature (pdf. format) and information about the tests (examples of the best done) and final exam.

Studio project 3 - Urbanism is compulsory course at fifth semester at Bachelor studies. It focus on the urban regeneration and design of selected location in Belgrade. Tutorial work is in studio and consider practical work on selected projects, field visits, recommendation of selected literature and preparation of graphical work. There are 12 studios and each studio has got between 20 and 25 students.

At the end of the summer semester, during 2014/15 a survey was done among 215 students who attended the course Urban design of open public space and 25 students from Studio project 3 - Urbanism about their experience with learning and gaining information through AMRES and faculty server and about possible improvements of communication and transfer knowledge via ICT between professors and students.

The questionnaire will show the attitudes among students in using e/learning service of AMRES at the specific subject. The questionnaire is structured as closed one where students were asked to answer five questions with predefined answers:

1. Did you use AMRES e-learning service at the course Urban design of open public spaces?

a. Yes

b. No

2. How often did you use it?

a. daily

b. weekly

c. monthly

3. Would you like to be informed through system in future?

a. Yes

b. No

4. For which purpose did you used the service?

a. For downloading data

b. For getting information about the subject

c. For all purposes that would make qualitative improvements in the education process

d. I did not use the service

5. What are your suggestions for novelties in communication with teachers in future? 

a. SMS
b. Whatsapp
c. E-mail
d. Web portal inside the Faulty
e. $\quad$ Face to face consultations
f. All ways of communication,
g. Nothing mentioned above.

181 student out of 215 from the course Urban design of open public space claimed they used the service during the course (Chart 1), from which 100 of them used it weekly, 35 daily, 83 monthly (Chart 2).

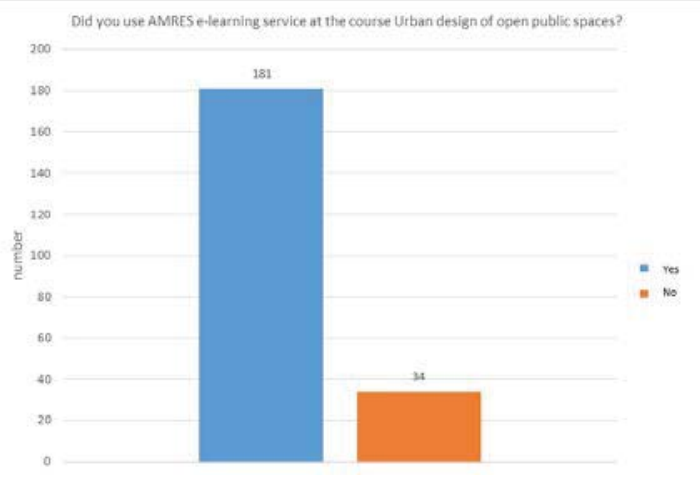

Chart 1.

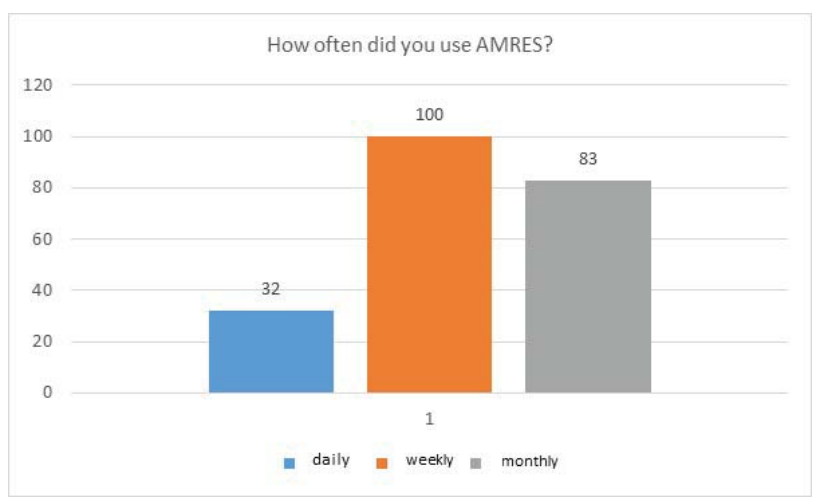

Chart 2.

On the question if they would like to be informed through the system in future 171 respond positively. Most of the examinees', 119 of them, used the service for all purposes that would make qualitative improvements in the education process. 19 of them for downloading the data, 43 for getting information about the subject, and 34 students did not used the service at all. Interesting fact is that 87 student chose e-mail for future correspondence with teachers, 22 of them Faculty's portal, Google groups 11 of the, SMS and WhatsApp are at the lowest range. Face to face communication is needed for 23 students among 215 and 7 students chose all ways of communication as necessary for qualitative teaching process $($ Chart 3,4$)$. 


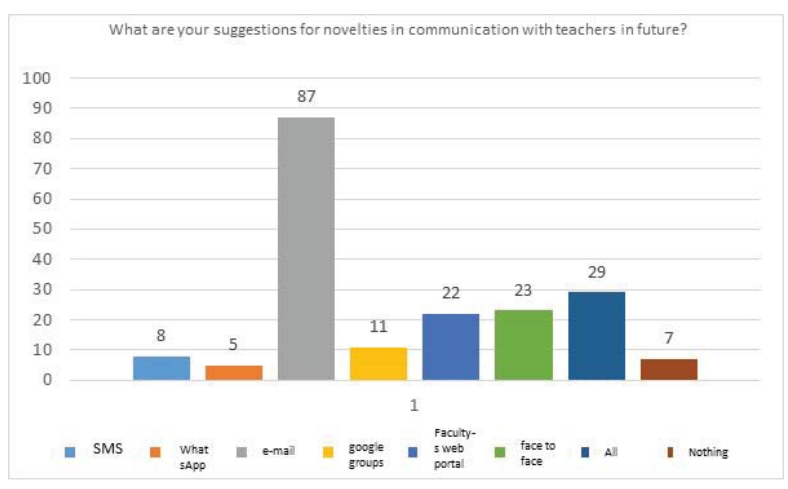

Chart 3.

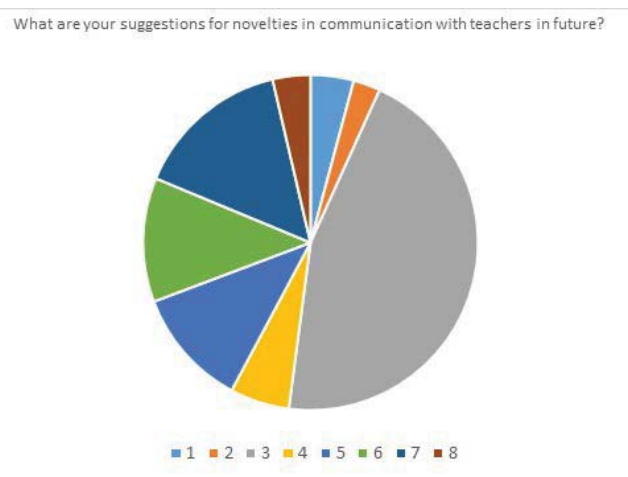

\section{Chart 4.}

12 student out of 25 from the course Studio project 3 - Urbanism claimed they used the service during the course from which 3 of them used it weekly, 1 daily, 8 monthly. On the question if they would like to be informed through the system in future only 6 respond positively. Most of the examinees', 7 of them, used the service for downloading the data, 5 for getting information about the subject, and 13 students did not used the service at all. Interesting fact is that 22 student chose e-mail for future correspondence with teachers, 12 of them Faculty's portal, Google groups 13 of the, SMS and WhatsApp are at the lowest range. Face to face communication is needed for 25 students among 25 and 4 students chose all ways of communication as necessary for qualitative teaching process.

The results shows that predominant attitude among students in future usage of ICT in education at the specific subject is in the range from moderate to radical, meaning students would integrate their everyday ways of communication into teaching process like e-mail, SMS, WhatsApp, google groups, blogs, etc. Even though most of them are for e-mail as another way of communicating, still there is a good percentage of them who prefer face to face consultative process especially the one who work in studio with tutors. Comparing the results from theoretical lectures and practical work in studio we can conclude that students who attend theoretical classes use AMRES more than one in studio. Overall conclusion regarding the hypothesis is that students tend to change their attitude regarding using ICT in education.

\section{CONCLUSION}

The paper discussed different approaches and attitudes that frame three predominant paradigms in integration of ICT in education system: The 
Technocrat, The Reformist, The Holistic. The approaches range from administrative to curricular, didactical, operational, systematic, cultural and ideological and in correlation with attitudes: agnostic, moderate, radical, extreme radical, maps the level of integration of ICT in everyday academic life. [1]

One of the research results are criteria for mapping approaches within specific form or model in usage of ICT: 1) number and quality of ICT equipment, network, security, 2) integration of usage ICT in overall curricula, 3) integration of usage ICT in specific curricula, tailor made ICT system, 4) moderate or high level of acceptance among users, 5) number and types of procedures, protocols, tools for using ICT in education, 6) integration of ICT in all organizational units in educational process, 7) Types and number of discussion groups in regards to ways of introducing ICT in specific curricula and overall educational process. According to criteria AMRES, specifically its e-learning service, is in between didactical and operational approach representing governmental ICT instrument for enabling collaboration between educational institutions, academic life, teachers, students. Therefore, it is a system that is in line with general curricula among faculties, providing functionalities to adopt to specific ones.

Measuring attitudes among students in usage of AMRES e-learning service at the ex-cathedra subject Urban design of open public spaces the most important fact is that students expressed an interest to widen functionalities of AMRES towards cultural approach as they showed moderate and radical attitude in integrating ICT into everyday educational life, using so called new web technologies such as e-mails, google groups, Faculty's web portal, while the students who attended classes in studio (at the course Studio project 3 Urbanism) were less interested and motivated to use AMRES and other ICT tools. Therefore, we can say and recommend that for this specific subject widening functionalities of AMRES and its integration with web portal of Faculty of Architecture in Belgrade is needed at theoretical classes in order to meet students' needs and attitudes. On the other hand Holistic paradigm and ideological approach are crucial for this kind of improvements [9], as large number of students expressed an interest for face to face communication.

Our guidelines (recommendations) for improvement of using AMRES in academic life are in line with general recommendations for ICT integration in education:

- "a well-defined institutional ICT strategy,

- a professional organization of the ICT-focused strategic process,

- the commitment and involvement of the institutional top-management,

- the need to link ICT to organizational development initiatives,

- the inclusion of ICT in human resource management activities, the internal marketing of ICT in the organization,

- the development of comprehensive and relevant documentation related to the process,

- the availability of financial resources,

- the availability of technical support and skills" [10:419]

\section{ACKNOWLEDGMENTS}

The paper is a result of a scientific research projects: Spatial, ecological, energy efficient and social aspects of settlement development and climate change interrelationships, financed by Ministry of education and science, Republic of 
Serbia, TR36035 and project III-44009 Development of embedded systems with connected services and digital technology.

\section{BIBLIOGRAPHY}

[1] Aviram, Roni and Tami, Debbie. "The impact on ICT in education: the three opposed paradigms, the lacking discourse. " Unpublished manuscript. Israel : Beer-Sheva University , 2004.

[2] Hawkridge, D., Who needs computers in school, and why? Computers and Education, No. 15, pp.1-6, 1990.

[3] Stephenson, J., ed., "Learner-managed learning- an emerging pedagogy for online learning. Teaching and Learning Online: Pedagogies for New Technologies. " London, Kogan Page, 2001.

[4] Oliver, R. "The role of ICT in higher education for the 21st century: ICT as a change agent for education ", Proceedings of the Higher Education for the 21st Century Conference, Curtin, 2003.

[5] Castells, M. "The Rise of the Network Society". Oxford: Blackwell Publishing, 2000

[6] W.J.Pelgrum. "Obstacles to the integration of ICT in education> results from a worldwide educational assessment". Computers \& Education, pp. 163-178, 2001

[7] RS. AMRES. https://www.amres.ac.rs. [Online] May 19, 2011.

[8] Bazik, D., Urban Design Technique Course: Education for Reflective Urban DesignerRequirements of Social, Economic and Professional Transition, in Reformae: handbook for European higher architectural education area, Siljanoska, J., Korobar, V. (eds.), Tempus SCM C019 A04, 2008

[9] Grosseck, G. "To use or not to use web 2.0 in higher education? ", Procedia Social and Behavioral Sciences 1, pp. 478-482., 2009.

[10] Stensaker, Bjorn, et al. "Use, updating and integration of ICT in higher education: Linking purpose, people and pedagogy., Higher Education, Springer, pp. 417-433, 20 